Doação de Sangue: Rompendo Barreiras com Alunos do Ensino Fundamental* Blood Donation: Breaking Barriers with Elementary School Students

\section{Palavras iniciais}

Há 25 anos surgia o projeto de extensão chamado "Sangue: vencendo o medo, garantindo a Vida", que atua na promoção da vida através do incentivo à doação de sangue. Para contextualizar a situação, serão apresentadas algumas ações do projeto, o incontestável envolvimento dos participantes e a mais surpreendente das atividades desenvolvidas: abordagem da doação de sangue para alunos do ensino fundamental. Todas as atividades são pensadas com base na simbologia dos indivíduos, pois, como afirma Benetti ${ }^{1}$ os símbolos surgem de vivências individuais, mantidas pela convivência social dentro de um contexto cultural. Como o mundo recebe sentido dentro desse movimento, caberia ao enfermeiro, dentre outras funções, desconstruir os significados negativos pertinentes ao sangue.

\section{Pinceladas de uma longa trajetória}

Tudo começou em 1988, com o Dia UERJ de Doação de Sangue, campanha realizada com o Instituto Estadual de Hematologia em um ônibus, estacionado atrás do prédio da Faculdade de Enfermagem. Tempos depois, a coleta foi transferida para o campus universitário Maracanã, mobilizando, principalmente, estudantes dos inúmeros cursos de graduação da Universidade do Estado do Rio de Janeiro. A parceria com o Banco de Sangue Herbert de Souza teve início em 1990, logo após sua criação no Hospital Universitário Pedro Ernesto (HUPE) e se mantém até os dias atuais. Prosseguiu com a realização de campanhas no campus universitário e no próprio banco de sangue, no período pré-carnavalesco, considerado como época crítica em qualquer instituição de saúde. A divulgação é feita no comércio local, em casas e edifícios do bairro de Vila Isabel. Nas salas de espera dos ambulatórios do HUPE,

\section{Raissa Muniz Figueiredo' e Liany Bonilla da Silveira Comino}

\begin{abstract}
Resumo
O projeto de extensão "Sangue: vencendo o medo, garantindo a Vida" atua na promoção da vida por meio do incentivo à doação de sangue. Um de seus eixos de atuação é desenvolvido em duas escolas no município do Rio de Janeiro, tendo por propósito sensibilizar e aproximar as crianças da doação de sangue. Estratégias lúdico-educativas adotadas facilitam e tornam a temática do sangue mais atraente. Ao longo do ano escolar, é desenvolvido um conjunto de atividades abrangendo: identificação da simbologia do sangue, exibição de desenho animado, teatro de fantoche, jogo educativo, visita ao Banco de Sangue Herbert de Souza do Hospital Universitário Pedro Ernesto, concurso de frases sobre a doação, cerimônia de encerramento com premiação e entrega de certificados de participação. O trabalho com os professores da escola possibilita a construção compartilhada da programação, a correlação com temas específicos e transversais curriculares, resultando em grande envolvimento das crianças irradiado para as famílias. Entender que os colegas de classe um dia poderão salvar vidas de outros remodela toda a noção de coletividade e humanismo. A doação de sangue é indispensável enquanto não houver pleno substituto, o que justifica todo esforço despendido nesse permanente e imperativo desafio.
\end{abstract}

Palavras-chave: Doação de Sangue; Processo Educativo; Escolares.

Área Temática: Saúde

Linha de Extensão: Saúde Humana
Bolsista de Extensão. UERJ. E-mail: raissa.muniz26@gmail.com * Coordenadora do projeto de extensão. UERJ. E-mail: liany@unisys.com.br * Redação expandida vencedora do III Prêmio de Extensão Professora Maria Theresinha do Prado Valladares. 
são abordados pacientes e acompanhantes, visando a dirimir dúvidas relativas à doação e captar doadores. A Oficina de Multiplicadores, iniciada em 1992, tem como propósito aproximar os alunos do $1^{\circ}$ período de Enfermagem e de outros cursos das questões que envolvem a história da hemoterapia, a legislação atual e a captação de doadores. Essa é a primeira atividade na qual os bolsistas adquirem conhecimento e interesse pelo projeto.

\section{Envolvimento pessoal e novos valores}

A professora coordenadora é portadora de larga experiência, determinação e entusiasmo pela captação de doadores, tendo participado, com outra docente da Faculdade de Enfermagem, de reuniões na Fundação Oswaldo Cruz para discutir e planejar ações de enfrentamento da crescente contaminação das transfusões sanguíneas, nos idos da década de 1980. Daí surge a iniciativa de buscar estratégias de educação em saúde, originando posteriormente as ações voltadas para crianças. $O$ trabalho realizado tem proporcionado crescimento acadêmico e pessoal inestimáveis, tanto para alunos bolsistas quanto para os voluntários participantes. Pode-se afirmar que a vida dá um salto, já que o entendimento sobre a saúde e as pessoas torna-se mais profundo e abrangente. Desenvolve-se a capacidade de falar em público, de interagir com pessoas de diferentes faixas etárias, de identificar, de agregar conhecimento e de estudar fatores determinantes da resistência à doação de sangue. Integrantes do projeto, em decorrência da atividade extensionista, tornam-se doadores de sangue em prol de uma grande causa social: a defesa da vida, decorrente da contribuição para a sobrevivência de milhares de pessoas. Bolsistas e ex-bolsistas, mesmo depois de graduados, estabelecem uma relação de apoio e encorajamento, permitindo a continuidade dessa iniciativa. A sensação de pertencer a um grupo tão unido é singular. Os laços de amizade transcendem o período de atuação no projeto, perpetuando os encontros, o afeto e as lembranças.

\section{Coisas e Loisas sobre um líquido precioso: o Sangue}

O trabalho mais inusitado é a ação com alunos do ensino fundamental. No primeiro momento, aparece a indagação: falar sobre doação de sangue para crianças?
Em 1994, iniciou-se a realização de atividades educativas sobre o sangue e suas partes com escolares na Feira de Prestação de Serviços, durante o evento UERJ Sem Muros. Há quinze anos, grupos de escolares dos $2^{\circ}$ e $5^{\circ}$ anos do ensino fundamental são abordados sistematicamente, ao longo do ano letivo, por acreditar-se que a educação consiste em instrumento de mudança de comportamento e que a escola é um agente de socialização de conhecimentos.

Sobre isso, Borsa ${ }^{2}$ afirma:

[...] a escola exerce um papel importante na consolidação do processo de socialização, processo esse que ocorre já no início da vida da criança. A escola será determinante para o desenvolvimento cognitivo e social infantil e, portanto, para o curso posterior de sua vida. É na escola que se constrói parte da identidade de ser e pertencer ao mundo; nela adquirem-se os modelos de aprendizagem, a aquisição dos princípios éticos e morais que permeiam a sociedade; na escola depositam-se as expectativas, bem como as dúvidas, inseguranças e perspectivas em relação ao futuro e às suas próprias potencialidades.

O argumento reforça a importância da educação fundamental e o cuidado necessário no processo de formação. Nesse movimento, o conjunto de atividades, intitulado Coisas e Loisas sobre um Líquido Precioso, tem por finalidade introduzir a discussão sobre a importância, as condições básicas ${ }^{3}$, os mitos e os tabus acerca da doação de sangue, além de estimular as crianças a divulgarem o tema junto às suas famílias. Realizado em um colégio de aplicação e em uma escola municipal do Rio de Janeiro, o projeto pode ser uma maneira eficiente de aumentar o persistente e indesejável índice de doadores de sangue, que alcança menos de $2 \%{ }^{4}$ da população brasileira. $\mathrm{O}$ desenvolvimento de novas e precoces estratégias está ancorado no diálogo, construção, acompanhamento e avaliação conjuntos com os professores, permitindo estabelecer também relações com temas transversais curriculares.

Os temas, preconizados pelo Ministério da Educação ${ }^{5}$, devem ser abordados ao longo da trajetória escolar. Seus eixos são atuais, urgentes e de âmbito nacional, e referem-se à ética, à saúde, ao meio ambiente, à pluralidade cultural e à orien- 
tação sexual. De forma direta, o projeto está mais relacionado com a ética, por tratar da valorização e do respeito à vida, e da tomada de decisão responsável. Outro viés é a própria saúde, porque traz informações apropriadas sobre a importância do sangue e a necessidade da doação.

Para tornar o assunto interessante e compreensível, a execução da proposta toma como base o conhecimento do aluno e de suas vivências, e ocorre por meio de atividades lúdico-educativas, desenvolvidas em sequência ao longo do ano letivo.

A simbologia do sangue possibilita conhecer o imaginário trazido pelas crianças, a partir do qual as ações são iniciadas. $\mathrm{O}$ desconhecimento da temática a ser abordada e do nome do projeto pelos escolares consiste em condição para evitar interferências em suas primeiras manifestações.

A exibição do desenho animado "Em Busca da Doação Perdida" atrai duplamente a atenção dos espectadores: por ser uma animação, as crianças já demonstram interesse por esse formato de apresentação; e a narrativa empolgante gera expectativa por um desfecho positivo. $\mathrm{O}$ desenho expõe a história de uma criança que necessita ser transfundida. Solidariamente, ocorre a mobilização de seus coleguinhas em busca de doadores de sangue. Durante a apresentação, eles descobrem e tomam conhecimento do que é um banco de sangue, de quem pode doar, das etapas da doação, entre outros. No final da história, ocorre a recuperação e o retorno do menino às atividades normais. Na discussão sobre o filme e os conhecimentos apreendidos, a maioria das crianças participantes demonstra alegria ao ver que é possível ajudar a salvar vidas pela doação.

O teatro de fantoches, elaborado pelos bolsistas do projeto, também diverte, fixa conhecimentos e aborda o baixo quantitativo de bolsas de sangue existentes nas instituições de saúde.

Ainda na gama de estratégias de avaliação, os jogos educativos desempenham papel fundamental, sobretudo o "Caminho da Vida", produzido pela equipe do projeto. Nele, são usadas perguntas elaboradas por crianças de outras turmas participantes sob a orientação dos professores da escola. O "exercício-brincadeira" consiste em mais uma forma de fixação e avaliação de conhecimentos.

Outra atividade especial é a visita ao Banco de Sangue Herbert de Souza (do HUPE), que ense- ja a correlação entre os conteúdos discutidos e o "caminho do doador de sangue: o cadastro, a triagem clínica, a sala de coleta, a copa e o laboratório de fracionamento". É o momento no qual a doação de sangue pode ser vista e entendida como um procedimento simples e recompensador para os doadores.

O concurso de frases é mais um instrumento de fixação e de avaliação final. Através dele, verifica-se o nível de incorporação dos conteúdos abordados. A cerimônia de encerramento anual compreende manifestações espontâneas das crianças e professoras envolvidas sobre as atividades realizadas, premiação do concurso de frases e entrega de certificados de participação dos escolares. $\mathrm{O}$ ambiente de confraternização propicia observação sobre atitudes e conhecimentos apreendidos pelos alunos, estreitamento de laços de convivência social e, como eles mesmos afirmam, a sensação de sentirem-se "adultos"; em outras palavras, seres com mais entendimento do significado da vida. Os resultados são claramente evidenciados através das avaliações escritas realizadas com os escolares, sempre um ano após sua participação, do depoimento de professores e de estudos realizados.

\section{Resultados concretos e simbólicos}

Desde o início do projeto nas instituições de ensino, em 1998, o número de crianças envolvidas é de aproximadamente 750 pessoas. Para ilustrar o envolvimento dos participantes, são apresentados alguns dados da avaliação da turma de 2011, frases de alunos das duas escolas e a fala de uma professora.

A quase totalidade das crianças envolvidas nas ações divulgou a doação de sangue em casa, irradiando para sua família a discussão sobre a temática. Cerca de um terço dos familiares, doou sangue devido a tal influência. A maioria dos escolares também afirma que doar não causa dor, não faz mal à saúde e declara que será doador ao atingir a idade recomendada.

Quanto às frases do concurso, destacam-se: "Doar sangue é quase fazer um amigo, então qual motivo de você não doar?", e "É importante doar sangue? Claro, é salvar vidas!" denotam sensibilização e solidariedade. "Doar sangue não dói, é só uma picada de mosquito e a gente nem sente a picada de mosquito, então por que ter medo de doar sangue?" e "Doar sangue não engorda ou emagrece, também não engrossa nem afina o sangue. Doar sangue não 
dói." ressalvam as boas informações que as crianças assimilam e podem socializar, seja sobre tipos de sangue ou sobre idade adequada para a doação. "A doação de sangue para mim é vida, prosperidade e energia. Traz tudo para nós, traz vida, traz amor, traz tudo de bom" sugere fortemente a mensagem positiva apresentada, não só pelo bem ao semelhante, mas também pela satisfação adquirida. Esse bem é reforçado por outra aluna que afirma: "Doação de sangue para mim é muito importante, porque você ajuda outras pessoas que você nem conhece; mas mesmo você não conhecendo, você estará fazendo parte de um mundo de doadores do bem". Há também leveza e humor, pois um deles sugere: "Não seja pão-duro. Doe sangue!”. Já a expressão "Construa um país melhor. Doe Sangue!" revela indício de empenho social. É emocionante perceber a receptividade, a agregação de novas atitudes e a pureza da fala das crianças, que expõem o que deveras sentem.

Esses resultados não só são evidenciados por parte dos alunos, como também demonstram o depoimento da professora pioneira das atividades desenvolvidas:

A discussão sobre o sangue teve início no $1^{\circ}$ semestre/98. Eu tive a felicidade de ser convocada por esse pessoal maravilhoso. Participei com a turma 403 composta por adolescentes que tinham muitas dificuldades. $\mathrm{O}$ projeto foi crescendo e o objetivo era transformar a ideia de violência vinculada ao sangue em representação de vida, em consciência de coletividade e de respeito pelo outro. Pessoalmente, eu superei o medo. Doei sangue pela primeira vez - uma data histórica, uma emoção tão grande!

Gestos nada dizem sobre o que sente quem participa de um trabalho como este.

\section{Dever cumprido e recompensa}

A atuação com os escolares recompensa a participação em iniciativa tão provocativa, que busca, desde a infância, transformar preconceitos e romper barreiras sobre a doação de sangue, utilizando "brincadeiras" para facilitar a compreensão. Constatar a mudança de atitude das crianças e perceber que elas poderão fazer a diferença é uma sensação singular. A atuação junto aos escolares resulta em transformação de postura, por trazer mais significados para o que as crianças entendem como vida e sangue. Para o escolar, saber que ele e outros colegas de classe poderão, no futuro, salvar vidas, remodela as noções de coletividade e humanismo. A doação de sangue é indispensável enquanto não houver pleno substituto, o que justifica todo o esforço despendido nesse permanente e imperativo desafio, mobilizando doadores em potencial e suas famílias.

\section{Referências}

1. BENETTI, Salete Regina Daronco. Vida e medo: significado atribuído ao sangue pelos doadores [dissertação]. Curitiba: Universidade Federal do Paraná, 2006.

2. BORSA, Juliane Callegaro. O Papel da Escola no Processo de Socialização Infantil. Disponível em: $<$ http://www. psicologia.pt/artigos/textos/A0351.pdf >. Acesso em: 27 jan. 2013.

3. Brasil. Ministério da Saúde. Portal da Saúde. Portaria Ministerial $\mathrm{N}^{\mathrm{o}}$ 1.353, de 13 de junho de 2011. Brasília, 2011.

4. Brasil. Ministério da Saúde. Sangue e Hemoderivados: Produção Hemoterápica. Brasília, 2011.

5. Brasil. Ministério da Educação. Parâmetros Curriculares Nacionais. Brasília, 1997.

6. Brasil. Ministério da Saúde. Hemocentro de Brasília. Em busca da doação perdida [CD-ROM]. Brasília, 1998.

\section{Abstract}

By encouraging blood donation, the Project "Blood: defeating fear, ensuring Life" acts on the promotion of life. One of its operation axis is developed in two municipal schools of Rio de Janeiro, Brazil. Its aims are to raise awareness and bring children closer to the actions of the program, making use of playful and educational strategies and making blood donation a more appealing subject. Some of the activities done during the school year are: how to interpret "Blood Symbolism"; cartoon watching; puppet shows; educational board games; visit to the Herbert de Souza blood bank - in Pedro Ernesto University Hospital in Rio de Janeiro; Best-sentence Contest and the Awards closing ceremony. The collaboration of teacher enebles the sharing of the programs and the correlation with both specific curriculum and transversal themes. These activities led to greater involvement of children and, consequently, of the family. The notion of collectivity and humankind gets renovated as they understand that their classmates can save lives. Blood donation is fundamental since there is no substitute for it This fact justifies all the effort spent in this permanent and imperative challenge.

Keywords: Blood donation; Education process; Scholars. 